\title{
Bronchogenic cysts in adults: frequently mistaken for a solid mass on computed tomography
}

\author{
Cornelis G. Vos ${ }^{1}$, Koen J. Hartemink ${ }^{1}$, Richard P. Golding ${ }^{2}$, J. Wolter A. Oosterhuis ${ }^{1}$, Marinus A. Paul ${ }^{1}$ \\ ${ }^{1}$ Department of Surgery, VU University Medical Center, Amsterdam, The Netherlands \\ ${ }^{2}$ Department of Radiology, VU University Medical Center, Amsterdam, The Netherlands
}

Received August 10, 2010, accepted after revision December 6, 2010, published online February 28, 2011

\section{Bronchogene Zysten bei Erwachsenen: Häufige computertomographische Fehldiagnose eines soliden Tumors}

Zusammenfassung. Zielsetzung: Bronchogene Zysten sind kongenitale Malformationen und werden häufig als Zufallsentdeckung bei asymptomatischen Patienten gefunden. Ein Wachstum dieser Zysten kann eine Kompression der Atemwegen und Blutgefäße verursachen, was zu klinischen Symptomen und möglichen Komplikationen führen kann. In der Computertomographie (CT) erscheinen bronchogene Zysten oft wie solide Tumore. Wir beschreiben in dieser retrospektiven Arbeit das diagnostische und therapeutische Management für Patienten mit bronchogenen Zysten.

Methoden: 11 erwachsene Patienten mit bronchogener Zyste wurden in eine retrospektive Fallstudie inkludiert. Die Mindestbeobachtungsdauer nach Diagnosestellung war 2 Jahre. Es wurde das Computertomogramm der Patienten erneut beurteilt und die Lokalisation, die Größe, die Hounsfield Einheiten (HU) und das Aussehen (zystisch $\leq 20$ HU oder solide $\geq 20 \mathrm{HU}$ ) der Läsionen festgehalten.

Ergebnisse: Acht der 11 in der CT gefunden Läsionen wurden als solider Tumor entsprechend den Hounsfield Einheiten interpretiert. Neun von den 11 Patienten wurden chirurgisch reseziert. Zwei asymptomatische Patienten wurden nicht operiert und sind im 2 jährigen Beobachtungszeitraum asymptomatisch ohne Wachstum der Zyste geblieben. Komplikationen der Resektion waren: 1 postoperative Blutung, 1 mehrmaliger Pneumothorax und ein Rezidiv der Zyste. Die Mortalität lag bei null.

Schlussfolgerung: Bronchogene Zysten werden häufig fälschlich in der CT als solider Tumor diagnostiziert. Wenn die CT inkonklusiv ist, kann mittels MRI oder Ultraschall (EUS) die Differentialdiagnose getroffen werden.

Correspondence: Cornelis G. Vos, MD, Department of Surgery,

VU University Medical Center, De Boelelaan 1117, 1081

HV Amsterdam, The Netherlands, E-mail: c.vos@vumc.nl
Summary. Background: Bronchogenic cysts are congenital malformations and are often detected in asymptomatic patients as an incidental finding. Growth can cause compression of airways and vessels, resulting in clinical symptoms and possible complications. On computed tomography (CT) scans, bronchogenic cysts frequently have the appearance of a solid tumor. We describe diagnostic strategy and management for patients with bronchogenic cysts.

Methods: Retrospective case study of 11 adults diagnosed with a bronchogenic cyst. The CT scan of all patients was revised and localization, size, Hounsfield Units (HU), and appearance (cystic or solid) of the lesions were reported. Lesions were arbitrarily considered cystic or solid when the radiographic density was below or above $20 \mathrm{HU}$, respectively.

Results: Eleven adults with a bronchogenic cyst were followed for at least 2 years after diagnosis. Eight of 11 detected lesions were judged as a solid lesion, based on the radiographic density (in $\mathrm{HU}$ ) on $\mathrm{CT}$ images. Nine of 11 patients were treated by surgical resection. Two asymptomatic patients were not operated and remained asymptomatic without enlargement of the cysts during 2 years follow-up. Complications of resection were postoperative bleeding $(n=1)$, recurrent pneumothorax $(n=1)$, and recurrence of the cyst $(n=1)$. No mortality was observed.

Conclusion: Bronchogenic cysts are frequently mistaken for a solid mass on CT scans. Further differentiation can be made by MRI or EUS when CT is inconclusive.

Key words: Bronchogenic cyst, pulmonary malformation, computed tomography, cyst, solid.

\section{Introduction}

Bronchogenic cysts are a result of abnormal budding of the embryologic tracheobronchial tree and are one of the most frequent occurring congenital malformations of the lower airways [1]. They are seen in the mediastinum and lung parenchyma [1]. Cysts that arise early during gesta- 
tion occur mainly within the mediastinum and seldom communicate with the bronchial tree. Intraparenchymal cysts develop from aberrant budding in a later stage and can have bronchial communication [2]. Bronchogenic cysts are benign lesions and are often detected in the asymptomatic patient as an incidental finding with imaging studies. However, further increase in size can cause compression of airways and vessels, resulting in clinical symptoms and sometimes even life-threatening complications $[3,4]$.

On a computed tomography (CT) scan they appear as a well-circumscribed mass. The content of the cyst can be serous or proteinaceous, the latter giving the cyst the appearance of a solid tumor $[5,6]$. Therefore a definitive preoperative diagnosis is frequently difficult to obtain. Surgical resection in the symptomatic patient is recommended [1, 2]. However, in asymptomatic patients, the indication for surgery is controversial because the natural history of bronchogenic cysts is unknown and an unknown percentage of asymptomatic patients remain undetected during life. We present a retrospective case study of 11 adults with bronchogenic cysts treated in the VU University Medical Center and we discuss diagnostic strategy and management of this malformation.

\section{Materials and methods}

In a retrospective case study, the medical records of all patients treated in our institution for a bronchogenic cyst between 2004 and 2009 were reviewed. Approval from the institutional review board was acquired for this study. Data on demographics, presenting symptoms, localization, management, surgical findings, complications, recurrence, and follow-up were collected. The CT scan of all patients was revised by a radiologist and localization, size, local behavior (such as airway compression), Hounsfield Units (HU) of the lesion, and the appearance (cystic or solid) were reported. The radiologist was not involved in the treatment and not aware of the findings and follow-up of the patients. Lesions were considered cystic when the radiographic density was between 0 and $20 \mathrm{HU}$ and solid if radiographic density was more than $20 \mathrm{HU}$, as reported before [5].

\section{Results}

\section{Patient characteristics}

Eleven adult patients were diagnosed having a bronchogenic cyst. Five patients were males, 6 were females. Median age was 52 years and ages ranged between 31 and 69 years. The follow-up period was at least 2 years after diagnosis (median 2; range 1-6).

\section{Presentation}

In our series 3 of 11 patients were asymptomatic and in these patients the cyst was found incidentally on a CT scan during follow-up for a non-related condition. In the 8 symptomatic patients, presenting symptoms were dyspnea $(n=3)$, dry cough $(n=3)$, dysphagia $(n=1)$, and recurrent pneumonia $(n=1)$. These presenting symptoms were clinically associated with the bronchogenic cyst that was found.

\section{Diagnosis}

In 10 of 11 patients a thoracic CT scan was performed. In one of these patients, 2 bronchogenic cysts were detected. Eight of 11 detected lesions were judged as a solid lesion, based on the radiographic density (in HU) on the CT-scanning images (Fig. 1). Three of 11 lesions were judged as cystic lesions based on the CT-scans (Fig. 2). In 1 patient a Magnetic Resonance Imaging (MRI) scan was performed which showed a cystic lesion. Eleven of 12 lesions were localized in the mediastinum and only 1 lesion was localized in the pulmonary parenchyma. In the group of symptomatic patients, 8 of 12 lesions were located in the mediastinum and 1 was located in the pulmonary parenchyma. In the group of patients without any bronchogenic cyst related complaints, all lesions were located in the mediastinum. Table 1 summarizes the diagnostic findings in all patients.

In 6 of 11 patients, CT-guided FNA was performed because the lesion was considered solid. In 1 patient this re-

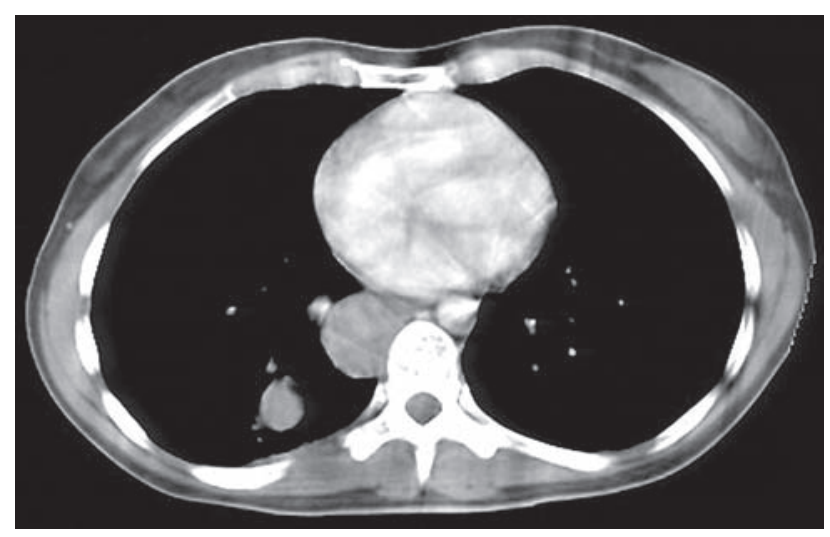

Fig. 1. Chest CT-scanning image of a bronchogenic cyst in the posterior mediastinum with slight compression of the left atrium. It has a high radiographic density of $70 \mathrm{HU}$ suggestive for a solid tumor. A second cyst is located in the right lung parenchyma

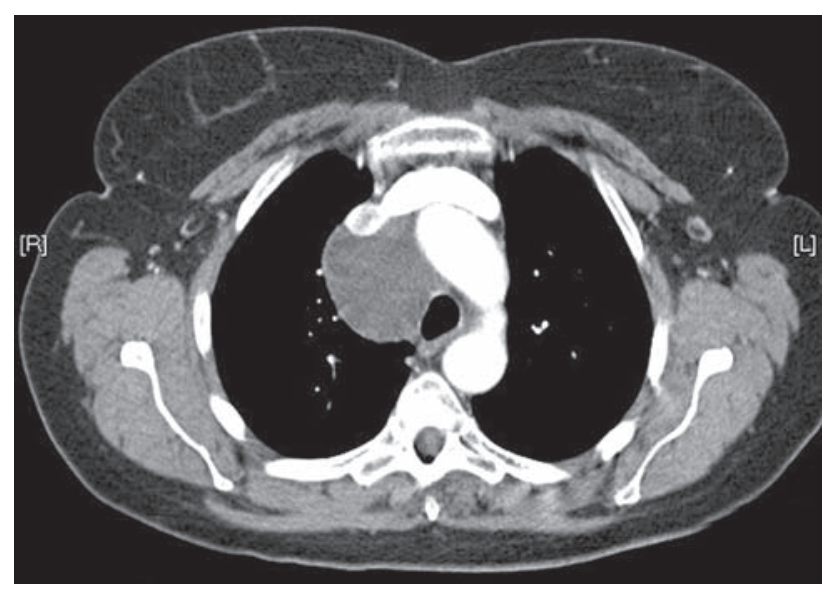

Fig. 2. Chest CT-scanning image of a bronchogenic cyst extending to the superior mediastinum with slight compression of the trachea. It has a low radiographic density of $10 \mathrm{HU}$ suggestive for a cystic lesion 
Table 1. Presenting symptoms and diagnostic findings

\begin{tabular}{lllccl} 
\# & Presentation & Location & $\begin{array}{l}\varnothing \\
(\mathbf{m m})\end{array}$ & HU & $\begin{array}{l}\text { Conclusion } \\
\text { radiologist }\end{array}$ \\
\hline 1 & Dry cough & Posterior mediastinum & 33 & 70 & Solid \\
& & Intrapulmonary & 18 & 57 & Solid \\
2 & Dry cough & Middle mediastinum & 60 & 43 & Solid \\
3 & Asymptomatic & Superior mediastinum & 14 & MRI & Cystic \\
4 & Asymptomatic & Middle mediastinum & 60 & 40 & Solid \\
5 & Dyspnea & Posterior mediastinum & 70 & 30 & Solid \\
6 & Dysphagia & Posterior mediastinum & 60 & 50 & Solid \\
7 & Asymptomatic & Superior mediastinum & 37 & 20 & Cystic \\
8 & Dyspnea & Middle mediastinum & 110 & 33 & Solid \\
9 & Dry cough & Middle mediastinum & 57 & 10 & Cystic \\
10 & Dyspnea & Middle mediastinum & 78 & 30 & Solid \\
11 & Recurrent & Posterior mediastinum & 80 & 20 & Cystic \\
& pneumonia & & & & \\
\hline
\end{tabular}

$\varnothing$, maximum diameter in $\mathrm{mm} ; \mathrm{HU}$, radiographic density in Hounsfield Units.

sulted in an infection of the cyst. In 4 of 6 punctured patients the cyst was found to be adherent to surrounding structures during surgical exploration, which made resection rather difficult. In 1 patient, the content of the cysts was completely aspirated but the cyst recurred and the patient was subsequently operated.

\section{Management}

Of the 11 patients, 9 were treated by resection. Eight patients had their cyst resected by thoracotomy and 1 by thoracoscopic surgery. One of the asymptomatic patients underwent resection because the pre-operative diagnosis was unclear and malignancy could not be ruled out. For the other 2 asymptomatic patients a wait and see policy was instituted and patients were followed by regular visits. After 3 years follow-up, they remained asymptomatic and the cysts did not demonstrate any increase in size.

For 8 of the 9 patients who were operated on, complete resection was possible. In 1 patient who had a diagnostic EUS-guided FNA before the operation, the cyst was extensively adhesive to the left atrium and the pulmonary artery, probably because of infection. Therefore, a part of the cyst wall remained in situ. This cyst recurred, and 1 year after operation, complete resection was performed through a contralateral thoracotomy.

One patient had 2 bronchogenic cysts, 1 in the mediastinum and 1 centrally located in the right lower lobe and presented with a persistent dry cough. For the mediastinal cyst an uncomplicated resection was performed. The intrapulmonary located cyst, with a diameter of $18 \mathrm{~mm}$, was removed by performing a lobectomy of the right lower lobe because of the central localization of the cyst. Nine of the 10 operated cysts contained a thick viscous fluid. One cyst contained a clear yellow-brownish fluid.

The diagnosis of bronchogenic cyst was confirmed by histologic analysis in all patients that underwent resection.

\section{Complications}

In 8 of the 11 patients, no complications were seen. In the group of patients that underwent resection, 6 of 9 patients did not have a complication. One patient needed a reoperation because of post-operative hemorrhage. Another patient was readmitted after an uncomplicated recovery because of recurrent pneumothorax which was treated by tube drainage. Finally, there was the above-mentioned recurrence after incomplete resection. No mortality was seen in our patients.

\section{Discussion}

Bronchogenic cysts are benign lesions which can cause symptoms by the compression of adjacent structures. They can be found in the mediastinum and pulmonary parenchyma, depending on the phase of gestation they develop in, with the majority of cysts $(60-80 \%)$ occurring in the mediastinum [2]. Risk of symptoms caused by compression of surrounding structures seems to be accounted for more by location of the cyst, than volume of the cyst, with cysts located in the superior mediastinum producing more symptoms than those located in the inferior mediastinum [7]. In pediatric patients, bronchogenic cysts are frequently seen as life-threatening emergencies with airway obstruction, atelectasis, and subsequent respiratory distress. In adults however, cysts are often asymptomatic or cause minor symptoms such as coughing, dyspnea, and substernal pain $[3,4,8,9]$.

Conventional chest radiographs can identify a mediastinal mass, however, for the final diagnosis they are of little value [8]. A CT scan can identify bronchogenic cysts. However, as confirmed by our present study, frequently a bronchogenic cyst has a high number of HU approaching those of solid tumors instead of the low density of water, expected in a cyst. This is explained by the fact that bronchogenic cysts can contain proteinaceous fluid resulting in high HU seen on a CT scan $[5,6]$. Our findings are confirmed by previous studies that demonstrating that bronchogenic cysts frequently have high HU resembling those of soft-tissue or solid tumors $[5,10]$. On the other hand, McAdams et al. found cysts with a radiographic density higher than $20 \mathrm{HU}$ in 25 out of 62 patients [11]. Only 7 of these were described as a solid mass. This difference is explained by the fact that they classified lesions with HU above 20 as soft tissue, instead of solid attenuation. However, to confirm the cystic nature of a lesion based on HU, we considered lesions with values below $20 \mathrm{HU}$ as cysts. In other cases magnetic resonance imaging can be used to identify bronchogenic cysts, and discriminate between solid and cystic masses, especially in cases with a high number of HU, giving an intense signal on T2-weighted MRI [12-14]. Alternatively, an EUS can usually distinguish between cystic and solid lesions, depending on location of the cyst in relation to the esophagus $[9,15]$.

Diagnostic FNA should be avoided because it can introduce infection or mediastinitis $[9,16]$. These infections make resection more complicated because of infection re- 
lated adhesions, which was seen in 4 of our 6 patients in which resection was difficult due to adhesions.

For diagnostic purposes, CT scanning is advised and complementary EUS can be of value in differentiating between a solid or cystic lesion. FNA is not necessary for the diagnosis.

For symptomatic cysts, surgical resection is generally advocated [2]. However, controversy remains for asymptomatic patients. Some authors state that resection of the asymptomatic cyst is indicated, because once they become symptomatic, resection is more difficult and increases the risk of complications $[2,7]$. It was observed before that in a series of 86 patients, $72 \%$ were symptomatic and $82 \%$ had a cyst that was either symptomatic or complicated (i.e. infection, hemorrhage within the cyst or ulceration of the cyst wall) [2]. Additionally, in $44 \%$ of the symptomatic patients, major operative difficulties or intraoperative complications were encountered. Therefore, resection of all bronchogenic cysts was recommended [2]. Clear evidence mandating surgical resection in asymptomatic patients is not available and long-term follow-up of asymptomatic cysts is lacking. The risk of malignancy developing in bronchogenic cysts is very small although incidental cases have been described [7, 17-19]. In our study, 2 patients were not operated but observed over a 3-year period. After 3 years, the cysts showed no increase in size and the patients did not develop any symptoms. Limitations of conservative treatment are lack of histologic confirmation of the bronchogenic cyst and the inability to rule out malignancy.

Total enucleation of the cyst is the treatment of choice. Incomplete resection or aspiration of the cyst results in high recurrence and complication rates [20-22]. If complete resection is impossible, de-epithelization of the remaining cyst wall may prevent recurrence [20-22]. Surgical morbidity after resection of bronchogenic cysts is low. In our study, as well as previous reports [2], no mortality was observed and a low rate of minor complications occurred.

\section{Conclusion}

Bronchogenic cysts are frequently mistaken for a solid mass on CT scans. Further differentiation can be made by MRI or EUS when CT is inconclusive.

\section{Conflicts of interest}

None to report.

\section{References}

1. Rodgers BM, Harman PK, Johnson AM. Bronchopulmonary Foregut malformations: the spectrum of anomalies. Ann Surg 1986;203:517-24.
2. St-Georges R, Deslauriers J, Duranceau A, et al. Clinical spectrum of bronchogenic cysts of the mediastinum and lung in the adult. Ann Thorac Surg 1991;52:6-13.

3. Bailey PV, Tracy T Jr, Connors RH, deMello D, Lewis JE, Weber TR. Congenital bronchopulmonary malformations: diagnostic and therapeutic considerations. J Thorac Cardiovasc Surg 1990;99:597-603.

4. Eraklis AJ, Griscom NT, McGovern JB. Bronchogenic cysts of the mediastinum in infancy. N Engl J Med 1969;281:1150-5.

5. Mendelson DS, Rose JS, Efremidis SC, Kirschner PA, Cohen BA. Bronchogenic cysts with high CT numbers. Am J Roentgenol 1983;140:463-5.

6. Nakata H, Nakayama C, Kimoto T, et al. Computed tomography of mediastinal bronchogenic cysts. J Comput Assist Tomogr 1982;6:733-8.

7. Wildi SM, Hoda RS, Fickling W, et al. Diagnosis of benign cysts of the mediastinum: the role and risks of EUS and FNA. Gastrointest Endosc 2003;58(3):362-8.

8. Patel SR, Meeker DP, Biscotti CV, Kirby TJ, Rice TW. Presentation and management of bronchogenic cysts in the adult. Chest 1994;106:79-85.

9. Ribet ME, Copin MC, Gosselin BH. Bronchogenic cysts of the lung. Ann Thorac Surg 1996;61:1636-40.

10. Aktogu S, Yuncu G, Halilcolar H, et al. Bronchogenic cysts: clinicopathological presentation and treatment. Eur Respir J 1996;9:2017-21.

11. McAdams HP, Kirejczyk WM, Rosado-de-Christenson ML, et al. Bronchogenic cyst: imaging features with clinical and histopathologic correlation. Radiology 2000;217:441-6.

12. Kanemitsu Y, Nakayama H, Asamura H, Kondo H, Tsuchiya $\mathrm{R}$, Naruke T. Clinical features and management of bronchogenic cysts: report of 17 cases. Surg Today 1999;29:1201-5.

13. König R, Herold U. Nuclear magnetic resonance detection of a mediastinal bronchogenic cyst. Radiologe 1986;26:464-6.

14. LeBlanc J. Imaging of mediastinal foregut cysts. Can Assoc Radiol J 1994;45:381-6.

15. Lim LI, Ho KY, Goh PM. Preoperative diagnosis of a paraesophageal bronchogenic cyst using endosonography. Ann Thorac Surg 2002;73:633-5.

16. Ryan AG, Zamvar V, Roberts SA. Iatrogenic candidal infection of a mediastinal foregut cyst following endoscopic ultrasound-guided fine-needle aspiration. Endoscopy 2002;34:838-9.

17. Greenfield LJ, Howe JS. Bronchial adenoma within the wall of a bronchogenic cyst. J Thorac Cardiovasc Surg 1965;49:398404.

18. Bernheim J, Griffel B, Versano S, Bruderman I. Mediastinal leiomyosarcoma in the wall of a bronchial cyst. Arch Pathol Lab Med 1980;104:221.

19. Olsen JB, Clemmensen O, Andersen K. Adenocarcinoma arising in a foregut cyst of the mediastinum. Ann Thorac Surg 1991;51:497-9.

20. Walker OM, Zumbro GL, Treasure RL. Bronchogenic cysts: problems in diagnosis and management. Thoraxchir Vask Chir 1978;26:59-64.

21. Miller DC, Walter JP, Guthaner DF, Mark JB. Recurrent mediastinal bronchogenic cyst. Cause of bronchial obstruction and compression of superior vena cava and pulmonary artery. Chest 1978;74:218-20.

22. Gallucio G, Lucantoni G. Mediastinal bronchogenic cyst's recurrence treated by EBUS-FNA with long term follow-up. Eur J Cardiovasc Surg 2006;29:627-9. 